\title{
Análise argumentativa em decisões judiciais de segundo grau: o tratamento da prova em vídeo em tribunais brasileiros
}

\section{Luís Felipe Leal de Moraes-Silva}

Mestrando em Direito e Inovação pela Universidade Federal de Juiz de Fora (UFJF), Brasil. luis.leal@direito.ufjf.br

\section{Amitza Torres Vieira}

Docente da Universidade Federal de Juiz de Fora (UFJF), Brasil. amitzatv@yahoo.com.br

\section{Vicente Riccio}

Docente da Universidade Federal de Juiz de Fora (UFJF), Brasil. vicente.riccio@gmail.com

Resumo: Este artigo analisa a configuração argumentativa de acórdãos para compreender o tratamento conferido à prova em vídeo na fundamentação de decisões judiciais. Analisaram-se dois julgamentos criminais, um do TJSP e outro do TJMG. A pesquisa é qualitativa e interpretativa (DENZIN; LINCOLN, 2006), e as análises foram empreendidas, integradamente, entre os campos da Linguística e do Direito. Marcas linguísticas revelaram se o vídeo foi assistido pelo magistrado e a importância dessa prova na construção da decisão tomada. Os resultados mostram que a forma de acesso ao vídeo, direta ou mediada por laudo pericial, não interferiu na decisão dos magistrados, pois, em ambos os casos, a evidência imagética foi valorada como convincente para a culpabilidade do réu. Em termos argumentativos, o vídeo, quando assistido, teve a mesma força que a prova testemunhal; e, quando acessado de forma mediada, constituiu o argumento mais forte da decisão.

Palavras-chave: Argumentação. Prova em vídeo. Evidência imagética. Força argumentativa.

\begin{abstract}
This article analyzes the argumentative configuration of judicial decisions to understand the treatment given by judges to video evidence at substantiating their decisions. Criminal judgments of appealing courts were analyzed, one from the state of São Paulo and another from Minas Gerais state, Brazil. It is a qualitative and interpretive research (DENZIN; LINCOLN, 2006), and the data analyzes integrated Linguistics and Law fields of knowledges. Linguistic markers revealed whether the video was watched and the importance of this evidence to the basis of those decisions. The results show that judges having access to the video by watching it or reading a report of it did not change the judgment they made. In both situations, the pictorial evidence contributed to support the culpability of the defendant. Argumentatively, when the video was watched, it held the same force as the testimonials; when examined through a report of it, it was the strongest argument of the decision.
\end{abstract}

Keywords: Argumentation. Video evidence. Pictorial evidence. Argumentative force. 


\section{Introdução'}

Diante de todo o percurso de desenvolvimento tecnológico trilhado pela humanidade, o empreendimento das tecnologias midiáticas, verificado a partir do século XX, altera profundamente o alcance e as formas de conexão entre os homens: as telecomunicações tornam realidade a comunicação em massa, e os aparelhos de multimídia, cada vez mais sofisticados, permitem o registro e o compartilhamento audiovisual dos acontecimentos em tempo real, além da produção de imagens no campo do universo fantástico.

A $30^{a}$ Pesquisa Anual do Uso de Tecnologia da Informação (FGV, 2019) estima que, neste ano, o Brasil tenha cerca de 420 milhões de "smartphones", número quase duplamente maior que a estimativa populacional do país para daqui a três décadas (IBGE, 2018). Se considerarmos que a câmera desses aparelhos é uma de suas funcionalidades mais importantes, não fica difícil compreender a profusão de imagens que especifica o contexto comunicativo contemporâneo. Essa apropriação tecnológica em larga escala produz efeitos em diversos âmbitos da organização social, tal como no campo do Direito, uma vez que os acontecimentos cotidianos registrados podem dizer respeito a eventos de relevância legal (episódios criminosos, por exemplo), transformando os arquivos audiovisuais em meios de prova, instituindo-se uma nova dimensão de argumentação jurídica (RICCIO et al., 2018, p. 86).

Pesquisas sobre o tema consideram que as imagens configuram um elemento retórico complexo. Sherwin (2011) afirma que nossos sentidos são altamente reativos às imagens, mesmo àquelas que não tenham sido produzidas dentro da lógica e da aparência do mundo físico que nos cerca, como é o caso das animações e outras produções ficcionais. Essa responsividade sensorial indica que o processo interpretativo das imagens em contextos judiciais, dada sua dimensão emotiva, implica mudanças no contexto forense contemporâneo, redefinindo a atuação dos operadores do Direito. Em uma cultura jurídica tradicionalmente determinada pela escrita e pela oralidade, nota-se a necessidade de uma alfabetização visual. Assim, tais inovações têm conduzido o sistema jurídico à necessidade de compreender as configurações dessa nova dimensão argumentativa nos tribunais.

\footnotetext{
${ }^{1}$ Os autores gostariam de agradecer o suporte financeiro da Fundação de Amparo à Pesquisa do Estado de Minas Gerais (FAPEMIG) ao projeto "A Prova em Vídeo nas Decisões de Segundo Grau: uma análise empírica acerca da interpretação judicial sobre a imagem” (APQ - 01236-16).
} 
Neste sentido, o objetivo geral deste trabalho é explorar a configuração argumentativa de decisões judiciais cujos autos apresentam a prova em vídeo como componente de seu arcabouço probatório. Especificamente, questionase: como o conteúdo do vídeo foi acessado pelo julgador: de forma direta (tendo-se assistido às imagens) ou de forma mediata (por meio de laudo pericial)? A prova em vídeo foi importante para o convencimento do juízo? Qual a força argumentativa que as imagens desempenham dentro da fundamentação da decisão?

Para responder a esses questionamentos, há que se debruçar sobre a linguagem empregada pelos magistrados em suas decisões, examinando-se o processo argumentativo empreendido e atentando-se para os elementos constitutivos do discurso judicial. Nesse sentido, a Linguística possui ferramentas que podem auxiliar na análise desses dados. Por exemplo, o estudo desenvolvido por Koch (2013) sobre argumentação e linguagem mostra como o uso de determinadas marcas linguísticas pode revelar a configuração argumentativa dos textos. Outros recursos linguísticos utilizados na argumentação, tais como nomes e verbos avaliativos, são apontados por Thompson e Hunston (1999) como indicadores da relação que o falante/escrevente subjetivamente estabelece com o seu discurso. Também estudos desenvolvidos por Vendrame (2006), cujo trabalho versa sobre construções enunciativas com verbos de percepção, podem auxiliar na análise textual dessas decisões para que seja possível compreender o processo interpretativo sobre a prova em vídeo.

Este trabalho se dá, assim, entre os campos da Linguagem e do Direito. Por se tratar de estudo exploratório desenvolvido a partir dessa interface disciplinar, adota-se uma perspectiva fenomenológica no exame dos dados. A metodologia de pesquisa é de cunho qualitativo e interpretativo (DENZIN; LINCOLN, 2006), e os dados analisados são provenientes de dois acórdãos de segunda instância: um do Tribunal de Justiça de São Paulo e outro do Tribunal de Justiça de Minas Gerais.

\section{Argumentação e marcas linguísticas}

O termo argumentação é bastante utilizado pela Linguística e pelas ciências jurídicas, mas possui especificações semânticas diferentes em cada 
campo. Na área do Direito, relaciona-se mais propriamente aos estudos da Teoria da Argumentação Jurídica. Esses estudos, embora possuam relação estreita com as teorias do discurso e também possam eleger como objeto de análise o discurso judicial, possuem orientação teleológica diferente daquela adotada neste trabalho ${ }^{2}$.

A análise argumentativa aqui empreendida localiza-se no campo da linguística textual, concebendo-se o discurso como uma resultante "das operações que controlam e regulam as unidades morfológicas, as sentenças e os sentidos durante o emprego do sistema linguístico" (MARCUSCHI, 1983, p. 30), de seu nível morfossintático à sua dimensão pragmática. Parte-se do pressuposto de que todo texto é dotado de argumentatividade, ideia que se ancora na concepção de que a linguagem é essencialmente atitudinal $(\mathrm{KOCH}$, 2013).

A abordagem proposta por Koch (2013) para o estudo da argumentação alia-se ao empreendimento analítico deste estudo, pois possibilita a interpretação de traços linguísticos vinculados ao contexto de uso. Os operadores argumentativos, por exemplo, são elementos gramaticais capazes de revelar a tessitura argumentativa dos textos: a direção a que os argumentos apontam e, em conjugação com o contexto, a força que desempenham na sustentação da conclusão. Nessa perspectiva, duas noções básicas são trazidas pela autora: a de "classe argumentativa" e a de "escala argumentativa". Quando dois ou mais enunciados servem de argumento para uma mesma conclusão, constituem uma classe argumentativa. Se as forças desses enunciados estiverem gradativamente orientadas, estabelece-se uma escala argumentativa, através da qual é possível depreender qual dos argumentos empregados teria a maior força no discurso.

Além dos operadores, a autora discute traços linguísticos capazes de apontar características subjetivas, como o estado psicológico do locutor/escritor e/ou sua atitude perante o que enuncia/escreve. Essas marcas, denominadas índices de avaliação e de atitude, pertencem às classes dos

\footnotetext{
2 Explica Toledo (2005, p. 49) que não é de questões como a semântica do discurso que a teoria da argumentação jurídica se ocupa, mas, por meio de uma perspectiva procedimental, visa a perscrutar de que maneira o discurso jurídico pode ser fundamentado racionalmente, partindo-se de uma dimensão discursiva ideal para parametrizar a realização do discurso. Nesse caso, argumentação tem a ver, então, com a justificação dos discursos legais conforme parâmetros hermenêuticos do próprio Direito.
} 
adjetivos e dos advérbios, além de expressões modais e de intensidade. São pistas linguísticas que atuam em textos argumentativos de forma a enfatizar o ponto de vista defendido pelo autor. Como afirmam Thompson e Hunston (2000), a avaliação expressa a opinião do falante/escrevente, refletindo o seu sistema de valores e o de sua comunidade. Os autores ainda acrescentam que, além dos adjetivos, nomes e verbos também podem desempenhar a função de índices avaliativos, como "sucesso", "tragédia”, “vencer”, "perder” etc.

Assim, essas marcas linguísticas podem revelar aspectos subjetivos que conectam o julgador e seu julgamento escrito, elucidando pontos de interesse da pesquisa, como o modo com que é avaliada uma determinada prova em vídeo de um processo e sua importância para a decisão dos julgadores.

Quanto a instrumentos para investigar como o conteúdo do vídeo foi acessado pelos magistrados, busca-se base teórica em Vendrame (2006), que estabelece diferentes categorias semânticas para predicadores verbais. Interessa a esta pesquisa, particularmente, o grupo dos verbos de percepção (ver, perceber, observar etc.) em contraponto aos verbos não perceptivos (descrever, demonstrar etc.).

Vendrame (2006) mostra que um falante/escrevente, ao enunciar uma informação, pode indicar o modo com que tal dado tenha chegado a seu conhecimento, de forma atestada ou de forma inferida. Para a autora, se o falante "viu" ou obteve a informação por meio de alguma outra forma sensorial, ele provavelmente utilizará um verbo de sentido para mostrar que a informação de que fala é atestada. Por outro lado, se a fonte originária da informação proferida não for o próprio falante/escrevente, a autora observa que a forma com que ele a obteve provavelmente tenha sido por meio de um relato, tratando-se da modalidade inferida. Desse modo, espera-se que a análise dos predicadores verbais possa indutivamente comportar o seguinte parâmetro: quando o julgador acessa o conteúdo da prova em vídeo tendo-a pessoalmente examinado, haja, nos trechos em que se aprecia a prova, o emprego de "verbos perceptivos"; e quando o julgador toma conhecimento do conteúdo do vídeo por meio de documentos descritivos, não o tendo assistido pessoalmente, sejam empregados verbos ausentes de traços de percepção. 


\section{Metodologia}

A metodologia de pesquisa é qualitativa e interpretativa (DENZIN; LINCOLN, 2006), pois focaliza os processos de construção de sentidos, tendo na linguagem o celeiro desta produção. No método qualitativo de pesquisa, os conceitos e as teorias emergem dos dados e são exemplificados neles. Há uma interação dinâmica entre os dados e a teoria. A pesquisa qualitativa procura descrever as principais ocorrências relevantes e faz uma correlação entre essas ocorrências e o contexto social mais amplo, a fim de que possam ser usadas como excertos concretos dos princípios abstratos que regem a organização social (ERICKSON, 1992).

Por se tratar de uma pesquisa de cunho exploratório, é necessário que a perspectiva de análise sobre os dados não esteja constrita ao referencial teórico adotado, a fim de que não se deixem de explorar novas revelações sobre os eventos investigados (YIN, 2010). Nesse sentido, adota-se uma perspectiva fenomenológica no tratamento dos dados, permitindo-se que a observação dos pesquisadores e seu processo interpretativo possam considerar, pragmaticamente, os diversos elementos constitutivos do discurso judicial - linguísticos e extralinguísticos - nas decisões selecionadas. Fica por isso inscrito, também, um viés etnometodológico na análise dos dados, sendo essa a orientação epistêmico-metodológica aqui adotada.

Os materiais desta pesquisa integram o acervo do projeto "A Prova em Vídeo nas Decisões de Segundo Grau: uma análise empírica acerca da interpretação judicial sobre a imagem", coordenado pelo Prof. Dr. Vicente Riccio, na Universidade Federal de Juiz de Fora. Seu banco de dados conta com aproximadamente mil acórdãos, extraídos das plataformas digitais dos tribunais de justiça dos estados de Minhas Gerais, São Paulo e Rio de Janeiro, todos referentes a processos em que foi empregada pelo menos uma prova em vídeo.

Acórdãos são, basicamente, a escrituração de julgamentos realizados por grupos de juízes em tribunais superiores (HENRIQUES, 1999), constando os votos de cada um e a decisão colegiada. Trata-se de um gênero textual cuja estrutura pode ser sintetizada em ementa (resumo do processo e da decisão), relatório (relato de todo o curso processual e da problemática em discussão) e dispositivo (votos, decisão e sua fundamentação). No caso deste trabalho, os 
acórdãos são decisões de segundo grau, em que os tribunais estaduais reexaminam os julgamentos proferidos pelos juízos inferiores - nas comarcas - quando pelo menos uma das partes, insatisfeita com a solução obtida em primeiro grau, resolve recorrer da decisão. Aceito o recurso pelo tribunal, é proferido julgamento, tendo-se examinado as manifestações dos sujeitos atuantes no processo, prototipicamente as partes autora e ré, e a própria decisão impugnada.

O contexto de produção dos discursos analisados, portanto, é institucional, localizado dentro do Poder Judiciário e orientado pelo ordenamento jurídico e pela argumentação desempenhada pelas partes. Em linhas gerais, é delineado, a priori, por três critérios fundamentais ${ }^{3}$, estabelecidos pela Constituição Federal ${ }^{4}$ : (i) todas as decisões judiciais devem ser juridicamente fundamentadas; (ii) antes de seu proferimento, as partes devem ser devidamente ouvidas; e (iii) a manifestação do poder judiciário está condicionada a que alguém a requeira. Por isso, pode-se afirmar, pelo menos em tese, que a atividade argumentativa desse tipo de discurso esteja subordinadamente orientada pelo seu contexto de produção, cenário que exprime uma evidente relação entre os elementos linguísticos e extralinguísticos que constituem os textos sob investigação.

Em razão do espaço do artigo, foram selecionadas como amostra para este trabalho decisões de duas instâncias: os Tribunais de Justiça de São Paulo e de Minas Gerais. Os excertos selecionados foram extraídos da parte dispositiva do acórdão.

O primeiro acórdão é o referente à apelação criminal nº 1.093.835.3/9-00, do Tribunal de Justiça de São Paulo, disponível para consulta no site da corte 5 . Em primeira instância, o réu fora condenado e recorre ao tribunal estadual no intuito de conseguir a absolvição. O apelante alega ser inocente do crime de abuso sexual contra menores, embora haja um vídeo que mostra a prática do delito, bem como depoimentos confirmando o tipo de contato do réu com as vítimas. A defesa alega que esses elementos probatórios não provam a autoria do crime.

\footnotetext{
${ }^{3}$ Sobre esses critérios, vide Cintra, Grinover e Dinamarco (2012).

${ }^{4}$ Disponível em: http://www.planalto.gov.br/ccivil_03/constituicao/constituicaocompilado.htm.

${ }^{5}$ Disponível em: encurtador.com.br/vGHOU
} 
O segundo acórdão, referente à apelação criminal n 1.0000.11.0780343/000 do Tribunal de Justiça de Minas Gerais, também disponível para consulta eletrônica ${ }^{6}$, trata de pedido de revogação de prisão temporária decretada contra o acusado em uma investigação policial pelo crime de tráfico de drogas. Segundo o acórdão, contra ele há imagens coletadas pela polícia que o mostram no local do crime interagindo com outros investigados. Afirma a defesa que a prisão deve ser extinta por carecer de fundamentação e por não haver os requisitos legais suficientes para a sua manutenção, aduzindo que o contato do postulante com o outro investigado se dá pelo fato de que são irmãos. Acrescenta, ainda, que o réu é primário e portador de bons antecedentes.

Quanto ao procedimento de análise dos dados, primeiramente, descreve-se o contexto jurídico em que o acórdão está inserido e se examina a estrutura argumentativa da decisão. Com base nessas informações, procedese à análise linguística, a fim de se responder às perguntas de pesquisa levantadas.

\section{Análise dos dados}

A análise apresenta, primeiramente, o trecho selecionado da decisão do Tribunal de Justiça de São Paulo.

\section{Excerto 1:}

(a) A autoria, por sua vez, foi provada graças aos depoimentos das jovens vítimas e à fita de vídeo que continha as gravações dos atos libidinosos praticados, em que se via nitidamente o apelante com as crianças.

(b) Os depoimentos colhidos demonstraram que o apelante inequivocamente cometeu os atos que lhe foram imputados.

$[\ldots]$

(c) Basta ler os depoimentos e assistir à fita de vídeo gravada pelo próprio apelante [...].

$[\ldots]$

De fato, ficaram seguramente demonstradas as práticas reiteradas de atos libidinosos aptos a satisfazer a lascívia do apelante, sendo de bom senso a manutenção da condenação.

\footnotetext{
${ }^{6}$ Disponível em: encurtador.com.br/hixA8
} 
O paradigma que orienta a atividade argumentativa do juízo sobre o caso, além da prévia atuação das partes no processo, é o Código Penal ${ }^{7}$, em que está previsto o crime pelo qual o réu foi condenado. Determina o regramento penal, basicamente, que a condenação esteja submetida à verificação de dois elementos principais ${ }^{8}$ : (i) a materialidade, que diz respeito à ocorrência do crime, e (ii) a autoria, que diz respeito à identificação de quem o tenha cometido, sendo esses, portanto, os requisitos que servem de base para a decisão. A análise do julgador, então, implica a formação de um juízo de evidencialidade sobre as provas.

No excerto, a conclusão do juízo é no sentido de que seja necessária a manutenção da condenação do apelante, entendimento orientado por três argumentos: (a) o de que a autoria esteja provada por meio dos depoimentos das vítimas e da fita de vídeo com cenas do próprio crime praticado; (b) o de que os depoimentos colhidos demonstram de forma inequívoca que o apelante cometeu os atos que Ihe foram imputados; e (c) o de que assistir à fita de vídeo gravada e ler os depoimentos colhidos sejam o bastante para se concluir pela culpabilidade do réu.

Em termos estruturais, então, diz-se neste trabalho que a tessitura argumentativa do excerto envolve duas operações argumentativas: a conclusão e a fundamentação. Os argumentos apresentados estão pontualmente vinculados ao paradigma legal, expondo a convicção do julgador sobre a materialidade e a autoria do crime. Nesse sentido, por estar a argumentação constrita ao ordenamento jurídico, emprega-se neste trabalho a expressão fundamentação infraordenada, a fim de caracterizar essa operação argumentativa estritamente ordenada pelo paradigma jurídico-contextual.

Para se referir às imagens, o magistrado emprega, nos argumentos (a) e (c), os verbos "ver" e "assistir" e o índice de avaliação "nitidamente". Por esses predicadores verbais serem intrinsecamente dotados de uma semântica perceptual, esse uso aponta para que o acesso do julgador ao conteúdo da evidência imagética tenha se dado por meio de uma experiência direta, tendo o juiz, por meio de seus próprios sentidos, empreendido o movimento cognoscente que o levou ao teor das imagens. Essa postura diretiva do

\footnotetext{
${ }^{7}$ Disponível em: http://www.planalto.gov.br/ccivil_03/decreto-lei/del2848compilado.htm

${ }^{8}$ Para detalhamento desses requisitos, vide Greco (2015).
} 
julgador no exame das imagens assinala, assim, o que se pode chamar de apropriação autônoma do processo interpretativo sobre a evidência imagética.

"Nitidamente", por sua vez, indica tanto o acesso não mediado ao conteúdo do vídeo quanto o valor probatório atribuído pelo juiz às filmagens: se é nítido o que se vê, o que se conhece a partir disso se aporta em um juízo de evidencialidade capaz de se opor a formulações contrárias, na medida em que se manifesta um saber empírico pessoalmente construído. Assim, além do traço semântico de percepção, apura-se nessa marca linguística um traço semântico de evidencialidade, dizendo respeito ao valor de convencimento atribuído à prova. Identifica-se essa característica também no emprego do verbo "ver" (o apelante com as vítimas), que apresenta no contexto uma extensionalidade semântica com sentido de constatação.

Passa-se ao aferimento da força argumentativa desempenhada pela evidência imagética na tessitura da fundamentação, comparando-a ao peso da prova testemunhal. Ainda em (a), o magistrado emprega o operador argumentativo "e" para articular esses elementos probatórios. Segundo a categorização proposta por Koch (2013), essa marca linguística concatena argumentos com igual força argumentativa, sugerindo-se que as provas em questão desempenhem forças equânimes no discurso que fundamenta a decisão. Quanto às marcas avaliativas, se o índice "nitidamente" - na medida em que revela o alinhamento do juiz às filmagens - confere força a essa prova, o advérbio "inequivocamente”, em (b), atribui ênfase também aos depoimentos, estando presente nesse avaliador o traço semântico de evidencialidade. Em (c), por meio do verbo "bastar" (e, novamente, pelo operador “e”), o juiz, justapondo a leitura dos depoimentos e o exame da fita de vídeo, encerra seu convencimento sobre a culpabilidade do réu, contemplando-os indistintamente. Ademais, pelo exame de outras partes do acórdão (p. 726-727), é possível verificar que, enquanto o vídeo é "nitidamente" expressivo à comprovação da materialidade do crime, os depoimentos apuram "inequivocamente" que tenha sido o apelante o seu autor. Tem-se, então, que o vídeo e os depoimentos desempenham forças argumentativas equânimes na fundamentação da decisão.

Pertinente notar, ainda, a diferença no tratamento interpretativo conferido a cada tipo de prova. Enquanto o magistrado avalia - profusamente 
- a prova testemunhal, concatenando diversos depoimentos, contrapondo suas narrativas e dirimindo eventuais contradições e inconsistências (p. 723; $726,727,728,729)$, a análise do vídeo, por mais que haja sido mencionado o laudo pericial (p. 725), é empreendida de forma concisa, bastando "assistir à fita de vídeo", "em que se via nitidamente o apelante” a praticar o delito.

Empreendidas nesse excerto as análises propostas, passa-se a analisar o excerto extraído do Tribunal de Justiça de Minas Gerais. Trata-se de parte da decisão proferida em primeira instância, que é utilizada pelo desembargador na construção de seu voto.

\section{Excerto 2:}

(a) Justifica a autoridade policial a necessidade da prisão para que as investigações possam fluir no sentido de apurar as condutas praticadas no contexto dos fatos ora sob foco da sanha policial sem interferências de qualquer ordem.

[...]

(b) Tenho que o laudo pericial dos arquivos de vídeo demonstra a frequência do réu na residência do investigado Manoel Neto Lopes de Almeida.

(c) Além disso, os fatos relatados pelo requerente alegando ser irmão do investigado "Manu" e ser primário e de bons antecedentes, por si só, não afasta a possibilidade de participação do delito, não mudando a situação fática ensejadora da decretação de prisão temporária.

(d) Ademais, o delito supostamente cometido pelo investigado gera danos à sociedade, que está assolada pela prática do tráfico ilícito de entorpecentes [...]. Em face do exposto, considerando remanescer os motivos ensejadores do decreto da prisão temporária dos indiciados, indeferi-lhes a alforria.

Neste caso, diferentemente do anterior, não se trata de condenar ou absolver o réu, uma vez que ainda se está no âmbito das investigações policiais, fase que antecede a acusação propriamente dita ${ }^{9}$. Trata-se da formação de um juízo de probabilidade sobre a culpabilidade do réu como requisito para a manutenção de sua prisão temporária.

Nesse caso, o paradigma que orienta a atividade argumentativa do juiz além das alegações das partes - é a Lei $n^{\circ} .7 \cdot 960 / 89^{10}$, que estabelece as condições necessárias para o cabimento desse tipo de prisão. Os requisitos são três: (i) haver, com base em qualquer prova admitida na legislação penal, fundadas razões no sentido de que o indiciado tenha praticado ou participado

\footnotetext{
${ }^{9}$ Sobre o sistema acusatório, vide Pacelli (2017).

${ }^{10}$ Documento acessível em: http://www.planalto.gov.br/ccivil_03/leis/l7960.htm.
} 
de algum dos crimes elencados pela lei; (ii) o investigado não possuir residência fixa ou deixar de apresentar elementos necessários para o esclarecimento de sua identidade; e (iii) a medida ser imprescindível para as investigações. Explica o jurista Pacelli (2017) que o cabimento da prisão temporária está condicionado, imprescindivelmente, ao atendimento do requisito (i), devendo-se cumulá-lo a pelo menos um dos outros dois. É esse o paradigma que visa a orientar a atividade argumentativa do juízo em questão.

A conclusão do magistrado é no sentido de que seja necessária a manutenção da prisão temporária do réu. A fundamentação é constituída por quatro argumentos: (a) a alegação da polícia de que a prisão seja necessária para evitar que as investigações sofram interferência; (b) a assunção de que o laudo pericial do vídeo atesta a frequência do réu na casa de outro investigado no mesmo inquérito; (c) a ponderação de que a alegação do acusado sobre ser irmão do investigado, primário e portador de bons antecedentes não seja capaz de afastar a possiblidade de sua participação no delito; e, por último, (d) a asserção de que o crime supostamente cometido pelo réu gere danos à sociedade, que estaria "assolada pelo tráfico ilícito de entorpecentes".

Em termos estruturais, então, as operações argumentativas que compõem a decisão são fundamentação e conclusão. Quanto aos argumentos, (a) e (b) estão em função, respectivamente, dos requisitos (iii) e (i) do paradigma legal. O argumento (c) aparece como resposta à afirmação da defesa sobre a primariedade do réu e sua relação de parentesco com outro acusado, e, embora não esteja vinculado aos requisitos da lei, seu emprego se dá em decorrência da argumentação da defesa. Assim, (a), (b) e (c) estão pontualmente orientados pelo paradigma jurídico-contextual. $\mathrm{O}$ argumento (d) representa uma asserção informal do juiz, não estando constrito aos liames que orientam formalmente a atividade argumentativa nesse gênero textual. Assim, se, no primeiro excerto, a fundamentação da decisão foi descrita como infraordenada, neste é possível caracterizá-la como fundamentação supraordenada, uma vez que colaciona argumentos vinculados e não vinculados ao referencial paradigmático.

Prosseguindo-se à análise das marcas linguísticas, em (b), afirma o juiz que o réu frequenta a casa de outro acusado, argumento empregado para assinalar a ideia de que o réu seja possivelmente culpado. Nesse trecho, o 
emprego do predicador "demonstrar" - por se tratar de um verbo desprovido de traço semântico de percepção - sugere que o conhecimento do julgador sobre o conteúdo do vídeo tenha se dado de forma indireta, não tendo ele assistido às gravações. Corroborando essa análise, a menção ao laudo pericial das imagens é outra pista textual que aponta nesse sentido, pelo que se conclui que o documento tenha atuado como elemento de mediação no exame da prova em vídeo. Por isso, considera-se ter havido uma apropriação heterônoma da interpretação das imagens, na medida em que o conhecimento do julgador sobre essa prova aporta-se em um documento descritivo, tendo o significado e a narrativa do vídeo sido construídos por outrem.

O valor indiciatório atribuído às imagens pode ser notado pelo emprego de "tenho", verbo que, dizendo respeito ao que constitui o convencimento do juiz e estando conjugado em primeira pessoa, revela seu alinhamento diante de sua afirmação em (b). Por esse uso, verifica-se que o magistrado valora essa prova como satisfatória ao juízo de probabilidade exigido.

Quanto ao peso argumentativo das imagens em relação aos demais argumentos, investiga-se como se dá a dinâmica de distribuição da força argumentativa no arranjo da fundamentação. A tessitura da decisão coordena os argumentos por meio do emprego de "além disso", em (c), e "ademais", em (d). Na perspectiva de Koch (2013), essas marcas linguísticas, por seu sentido básico de adição, concatenam argumentos com igual força em relação à conclusão, o que sugere, inicialmente, que (a), (b), (c) e (d) tenham forças equânimes na fundamentação do juiz, de maneira a conformar uma classe argumentativa.

Por outro lado, o paradigma que serve de orientação ao pronunciamento do juiz indica que o laudo da prova em vídeo tenha maior importância. Considerando-se que o atendimento ao requisito (i) da lei é imprescindível para o cabimento da prisão temporária, (b), por atender a esse requisito, é, em termos formais, o elemento mais importante para a decisão, validando o argumento (a) e, assim, viabilizando a própria aplicação da lei. Nesse caso, portanto, verifica-se a conformação de uma escala argumentativa topicalizada pelo laudo da evidência imagética, de modo que a importância dos argumentos na tessitura da fundamentação é contextualmente estabelecida, não estando linguisticamente marcada. 


\section{Considerações finais}

Neste trabalho, sob a motivação de compreender o tratamento da prova em vídeo no contexto forense, analisou-se a argumentação de juízes quando da fundamentação de seus vereditos, explorando-se a configuração argumentativa das decisões judiciais. No primeiro acórdão examinado, as análises mostraram que: (i) o conteúdo da evidência imagética foi acessado de forma direta, por meio de uma apropriação autônoma do processo interpretativo das imagens; (ii) a prova em vídeo foi valorada como convincente para o juízo de evidencialidade sobre a culpa do réu; (iii) enquanto argumento, desempenhou a mesma força argumentativa que a prova testemunhal quanto à tessitura argumentativa da decisão. Quanto ao segundo acórdão, as análises indicaram que: (i) o acesso ao conteúdo da prova em vídeo foi indireto, mediado pelo laudo pericial das imagens, por meio de uma apropriação heterônoma do processo interpretativo sobre a evidência imagética; (ii) o laudo pericial foi valorado como convincente para o juízo de probabilidade sobre a culpa do investigado; (iii) juridicamente, o laudo sobre as imagens é o elemento mais forte entre os argumentos empregados.

Assim, os resultados do estudo mostram que o fato de o acesso ao vídeo ocorrer de forma mediata ou imediata não interfere na decisão dos magistrados, pois, em ambos os casos, a prova imagética foi valorada como convincente para a culpabilidade do réu. Em relação à tessitura argumentativa dos discursos, quando o vídeo foi assistido pelo julgador, essa prova teve a mesma força que a prova testemunhal. Por outro lado, quando o julgador não assistiu ao vídeo, baseando-se no laudo pericial das imagens, essa prova constituiu o argumento mais forte da decisão.

Os traços semânticos identificados, de percepção e de evidencialidade, foram a característica linguística mais reveladora. A identificação do primeiro, como em "via", "assistir" e "nitidamente", tornou possível verificar se o julgador assistiu ou não ao vídeo; e a do segundo, em "via”, "nitidamente", "demonstraram", "inequivocamente" e "basta", indicaram o valor probatório atribuído às provas pelos magistrados. Palavras que desempenharam valor avaliativo, como "basta" e "tenho (que)", mostraram a importância das provas examinadas para a formação do convencimento do juízo. Identificouse, ainda, a atuação dos operadores argumentativos na organização textual da 
decisão. Assim, as marcas linguísticas mais producentes para as investigações deste estudo pertencem às classes gramaticais dos verbos, adjetivos, advérbios e conjunções.

$\mathrm{Na}$ medida em que este trabalho se inscreve nos estudos da língua em função, a investigação do tratamento à prova em vídeo nas decisões judiciais implicou explorar outros aportes argumentativos empregados pelos julgadores e o contexto jurídico-institucional. Desse modo, foi possível compreender mais amplamente as configurações argumentativas do discurso jurisdicional no âmbito dos dados analisados.

Por outro lado, nossos resultados são válidos tão e somente para os acórdãos aqui investigados, necessitando de confirmação que os validem em outros textos do gênero.

Por fim, espera-se que este estudo contribua para a compreensão do tratamento da prova em vídeo e de sua dimensão argumentativa no contexto forense, de modo que as análises empreendidas possam ser proveitosas tanto aos estudos da linguagem quanto ao campo jurídico.

\section{Referências}

BRASIL. Instituto Brasileiro de Geografia e Estatística. Projeção da População 2018: número de habitantes do país deve parar de crescer em 2047. Agência IBGE Notícias, 2018. Disponível em: https://agenciadenoticias.ibge.gov.br/pt/agencia-home.html. Acesso em: 25 jun. 2019.

CINTRA, Antônio Carlos de Araújo; GRINOVER, Ada Pellegrino; DINAMARCO, Cândido Rangel. Princípios Gerais do Direito Processual. In: CINTRA, Antônio Carlos de Araújo; GRINOVER, Ada Pellegrino; DINAMARCO, Cândido Rangel. Teoria geral do processo. 28. ed. São Paulo: Malheiros Editores, 2012, P. 59-83.

DENZIN, Norman; LINCOLN, Yvonna. O planejamento da pesquisa qualitativa: teorias e abordagens. 2. ed. Porto Alegre: Artmed, 2006.

ERICKSON, Frederick. Ethnographic microanalysis of interaction. In: The handbook of qualitative research in education. New York: Academic Press, 1992. p. 201-225.

FUNDAÇÃO GETÚLIO VARGAS. FGV EAESP, 2019. Página inicial. Disponível em: https://eaesp.fgv.br/ensinoeconhecimento/centros/cia/pesquisa. Acesso em: 25 jun. 2019. 
GRECO, Rogério. Conceito e evolução da teoria do crime. In: GRECO, R. Curso de direito penal. 17. ed. Rio de Janeiro: Impetus, 2015. cap. 21, p. 189-201.

HENRIQUES, Antônio. Prática da linguagem jurídica. 2. ed. São Paulo: Atlas, 1999.

$\mathrm{KOCH}$, Ingedore Grunfeld Villaça. A inter-ação pela linguagem. 11. ed. São Paulo: Contexto, 2013.

MARCUSCHI, Luiz Antônio. Linguística de texto: o que é e como se faz. Recife: Editora Universitária da UFPE, 1983.

PACELLI, Eugênio. Da Prisão, das Medidas Cautelares e da Liberdade Provisória. In: Curso de processo penal. 21. ed. São Paulo: Atlas, 2017. p. 501-618.

RICCIO, Vicente et al. Imagem e Retórica na Prova em Vídeo. Revista de Informação Legislativa. Brasília, a. 55, n. 220, p. 85-103, out./dez.2018.

SHERWIN, Richard K. Visualizing law in the age of the digital baroque: arabesques and entanglements. London: Routledge, 2011.

THOMPSON, Geoff; HUNSTON, Susan. Evaluation: an introduction. In: THOMPSON, Geoff; HUNSTON, Susan (org.). Evaluation in text: Authoral Stance and the Construction of Discourse. Oxford: Oxford University Press, 2000, p. 1-27.

TOLEDO, Cláudia. Teoria da Argumentação Jurídica. Revista Veredas do Direito. Belo Horizonte, v. 2, n. 3, p. 47-65, jan./jun. 2005.

VENDRAME, Valéria. Predicados de atitude proposicional como marcadores de evidencialidade. Estudos Linguísticos. São Paulo, v. XXXV, p. 1928-1936, 2006. Disponível em: encurtador.com.br/txGX3. Acesso em: 12 jan. 2019.

YIN, Robert K. Pesquisa qualitativa: do início ao fim. Tradução: Daniel Bueno. Porto Alegre: Penso, 2016.

\section{Forma de citação sugerida}

MORAES-SILVA, Luís Felipe Leal de; VIEIRA, Amitza Torres; RICCIO, Vicente. Análise argumentativa em decisões judiciais de segundo grau: o tratamento da prova em vídeo em tribunais brasileiros. EID\&A - Revista Eletrônica de Estudos Integrados em Discurso e Argumentação, Ilhéus, n. 19, v. 2, p. 93-108, dez.2019. DOI 10.17648/eidea19-v2-2445. 